\title{
Endoscopic fine needle aspiration cytology in the diagnosis of gastro-oesophageal and colorectal malignancies
}

\author{
S A Zargar, M S Khuroo, R Mahajan, G M Jan, K Dewani, V Koul
}

\begin{abstract}
In a prospective study we compared the diagnostic accuracy of endoscopic fine needle aspiration cytology with that of brush cytology and forceps biopsy in relation to gross tumour pattern and site in 265 confirmed consecutive cases of malignancy of the oesophagus, stomach, colon, and rectum. Aspiration cytology gave the highest diagnostic accuracy $(94 \%)$, which was significantly better than that of brush cytology $(84.9 \%)$ and biopsy $(87.2 \%)$ $(\mathbf{p}<0 \cdot 005)$. The difference was mainly related to tumour pattern. When compared to brush cytology and biopsy aspiration cytology was significantly better in submucosal tumours $(92.9 \% v 7.1 \%$ and $14.3 \%, p<0.001)$; in infiltrative malignancies $(95.8 \% v \mathbf{9 0} \cdot 1 \%$ and $78.9 \%$, $\mathbf{p}<\mathbf{0 . 0 1}$ ), and in ulceronecrotic malignancies $(90.9 \% v 36.4 \%$ and $45.4 \%, p<0.05)$. In polypoid malignancies there was a significant trend $(p<0.05)$ in favour of forceps biopsy, with a diagnostic yield of $100 \%$ compared with $95 \%$ for aspiration cytology and $\mathbf{9 3 . 3 \%}$ for brush cytology. The accuracy of the different techniques was not significantly related to the site of the tumour. The cumulative accuracy of aspiration cytology and biopsy was significantly better than that of biopsy and brush cytology (98.5\% v 90.9\%, p<0.005). Aspiration cytology was diagnostic in 21 of 24 lesions that were negative with both brush cytology and biopsy. There were no false positive cytology or histology results. We conclude that aspiration cytology is a simple, safe, and reliable technique with a high diagnostic yield and is of particular value in submucosal, infiltrative, and ulceronecrotic tumours.
\end{abstract}

Departments of Gastroenterology S A Zargar M S Khuroo

R Mahajan

Cytology

G M Jan

K Dewani

and Pathology

V Koul

Sher-i-Kashmir Institute of Medical Sciences, Srinagar, Kashmir, India 190011 Correspondence to:

Professor Mohammad Sultan Professor
Khuroo.

Accepted for publication 24 August 1990
Fibreoptic endoscopy has revolutionised the diagnosis of gastrointestinal disease. Currently, direct vision endoscopic brush cytology and forceps biopsy are the two standard techniques used to establish the preoperative diagnosis in gastrointestinal malignancies. ${ }^{1-5}$ When used in combination these techniques give false negative results in up to $5 \%$ of the lesions ${ }^{1-6}$ and this percentage further increases in infiltrative or stenotic lesions, ${ }^{367}$ malignancies with necrotic surfaces, ${ }^{3}$ and submucosal tumours such as lymphomas and sarcomas. ${ }^{7-9}$ Therefore, a new sampling technique is always justified if, as well as being safe, it increases the diagnostic yield.

Fine needle aspiration cytology is well recognised as a simple and reliable method for the definitive diagnosis of tumours detected by palpation or imaging techniques. With the avail- ability of the flexible sclerotherapy injector, aspiration cytology samples can also be obtained from gastrointestinal lesions visualised endoscopically. Recently, in two small series of patients endoscopic fine needle aspiration has been reported to be useful in diagnosing gastrointestinal malignancies. ${ }^{10-1}$

The purpose of this prospective study was to compare the diagnostic accuracy of endoscopic fine needle aspiration cytology, brush cytology, and forceps biopsy with the macroscopic appearances and site of the tumour in a large series of 318 patients who were suspected of having malignant lesions of the oesophagus, stomach, colon, and rectum at routine endoscopy.

\section{Methods}

Endoscopic forceps biopsy specimens and cytological specimens were obtained from 318 consecutive lesions suspected of being malignant at routine endoscopic examination: oesophageal 110; gastro-oesophageal region 39 ; gastric 101 ; colorectal 68. The samples were obtained using , forward viewing endoscopes (GIF-Q, GIF-Q10, CF-MB3R, and PCF-10; Olympus Optical, Japan) in the following sequence: needle aspiration, brush cytology, and forceps biopsy ( $\geqslant$ six pieces). Biopsy specimens were taken using forceps with a central spike and fenestrated cups with a diameter of $2 \mathrm{~mm}$. The specimens were fixed in $10 \%$ formalin and stained with haematoxylin and eosin. Additional stains were used as warranted. Cytology brushings were obtained with a non-disposable nylon sheathed brush and smeared on to slides. The slides were immediately fixed in $95 \%$ ethyl alcohol and then stained by the Papanicolaou method.

Fine needle aspirates were obtained using a $200 \mathrm{~cm}$ flexible sclerotherapy injector (Microvasive) with a $0.4 \mathrm{~cm} 23$ gauge retractable needle at its distal end. A $20 \mathrm{ml}$ disposable syringe was attached to the hub of the injector. After visualising the lesion to be investigated the injector was introduced through the biopsy channel of the endoscope and advanced to the surface of the target lesion. The needle was then pushed out beyond the protective sheath and introduced into the target lesion. Aspiration was performed by the needle moving back and forth under continuous negative pressure created by applying adequate and gentle suction with the syringe. The suction was gently released and the needle was withdrawn from the lesion. The procedure was repeated at another site. The needle was then retracted into the protective sheath before its removal from the forceps channel. The syringe was detached from the injector, filled with air, 
TABLE I Distribution of confirmed benign and malignant lesions

\begin{tabular}{|c|c|c|c|c|}
\hline & $\begin{array}{l}\text { Oesophagus } \\
(n=110)\end{array}$ & $\begin{array}{l}\text { Gastro-oesophageal } \\
\text { region } \\
(n=39)\end{array}$ & $\begin{array}{l}\text { Stomach } \\
(n=101)\end{array}$ & $\begin{array}{l}\text { Colon and rectum } \\
(n=68)\end{array}$ \\
\hline $\begin{array}{l}\text { Malignant } \\
\text { Benign }\end{array}$ & $\begin{array}{l}\text { Mucosal } 98 \\
\text { Submucosal 1 } \\
\text { Oesophagitis } 6 \\
\text { Stricture 4 } \\
\text { Tuberculosis 1 }\end{array}$ & $\begin{array}{l}\text { Mucosal } 37 \\
\text { Submucosal } 1 \\
\text { Adenoma } 1\end{array}$ & $\begin{array}{l}\text { Mucosal } 66 \\
\text { Submucosal } 6 \\
\text { Ulcer } 19 \\
\text { Gastritis } 6 \\
\text { Adenoma } 2 \\
\text { Leiomyoma } 2\end{array}$ & $\begin{array}{l}\text { Mucosal } 50 \\
\text { Submucosal } 6 \\
\text { Solitary rectal ulcer } 4 \\
\text { Adenoma } 6 \\
\text { Tuberculosis } 1 \\
\text { Actinomycosis } 1\end{array}$ \\
\hline
\end{tabular}

TABLE II Diagnostic accuracy of the three techniques in respect of the site of the malignancy

\begin{tabular}{lcccc}
\hline & \multicolumn{4}{c}{ No(\%) of positive cases } \\
\cline { 2 - 5 } Site of malignancy & $\begin{array}{l}\text { Total No of } \\
\text { cases }\end{array}$ & $\begin{array}{l}\text { Aspiration } \\
\text { cytology }\end{array}$ & Brush cytology & Forceps biopsy \\
\hline Oesophagus & 99 & $95(96)$ & $87(88)$ & $94(95)$ \\
Gastro-oesophageal region & 38 & $34(89)$ & $33(87)$ & $30(79)$ \\
Stomach & 72 & $68(94)$ & $61(85)$ & $63(88)$ \\
Colon and rectum & 56 & $52(93)$ & $44(79)$ & $44(79)$ \\
Total & 265 & $249(94)$ & $225(84.9)$ & $231(87 \cdot 2)$ \\
\hline
\end{tabular}

TABLE III Diagnostic accuracy of the three techniques in respect of gross tumour pattern

\begin{tabular}{lllll}
\hline \multicolumn{5}{c}{ No(\%) of positive cases } \\
\cline { 3 - 5 } Type of malignancy & $\begin{array}{l}\text { Total No of } \\
\text { cases }\end{array}$ & $\begin{array}{l}\text { Aspiration } \\
\text { cytology }\end{array}$ & Brush cytology & Forceps biopsy \\
\hline Primary carcinomas: & 120 & $114(95)$ & $112(93)$ & $120(100)$ \\
Polypoid & 71 & $68(96)$ & $64(90)$ & $56(79)$ \\
Infiltrative & 49 & $44(90)$ & $44(90)$ & $48(98)$ \\
Ulcerative & 11 & $10(90)$ & $4(36)$ & $5(45)$ \\
Ulceronecrotic & 251 & $236(94)$ & $224(89)$ & $229(91)$ \\
Total & 14 & $13(93)$ & $1(7)$ & $2(14)$ \\
Submucosal malignancies: & 265 & 249 & 225 & 231 \\
Total & & & & \\
\hline
\end{tabular}

and finally replaced to blow the aspirated material out of the reprotracted needle onto clean glass slides for making smears which were stained with May-Grunwald-Giemsa stain. Aspiration specimens from rectal lesions were obtained through a proctoscope using a 23 gauge lumbar puncture needle mounted on a suction syringe.

For patients undergoing more than one endoscopic evaluation only the results of the first examination were considered for data analysis. Biopsy material and cytology specimens were examined in two independent laboratories by different investigators without knowledge of the clinical history or endoscopic findings. Cytology specimens were interpreted as either positive or negative for malignancy using standard criteria. Biopsy and cytology specimens which were interpreted as suspicious were not included as positively diagnostic as this would have required reexamination. This policy was adopted to obtain an accurate diagnostic yield of the results and an assessment of the reported difficulty in distinguishing between benign atypia and malignancy. ${ }^{12}$ Biopsy and cytology specimens from each case were reviewed independently blind to avoid observer bias. The final diagnosis of malignancy was established by pathological examination of surgically resected specimens $(n=172)$ or concurrent forceps biopsy specimens with available clinical data and follow up compatible with malignancy $(n=93)$. The final diagnosis of benign disease was made on the following criteria: (a) both cytology and biopsy specimens were negative for malignancy; (b) confirmation of the healing of the lesion at repeat endoscopy; (c) the patient was disease free for at least one year from the initial diagnosis of the lesion.

On the basis of endoscopic appearances the lesions were classified as follows: (i) polypoid malignancy, which showed prominent lobulated intraluminal growth in the form of polypoid excrescences or irregular nodules with superficial erosion but no large ulceration; (ii) ulcerative malignancy, which showed two patterns: one with prominent intraluminal growth with deep ulceration and the other like an ulcer with radiating folds; (iii) ulceronecrotic malignancy, in which a large ulcerative tumour was covered with extensive necrotic slough; (iv) infiltrative malignancy, which showed diffusely thickened and infiltrated mucosa with tumour causing luminal narrowing and may be associated with erosion, shallow ulceration, or small nodular projections; (v) submucosal tumour, which showed single or multiple intraluminal nodular bulges or masses with normal intact mucosa. During the study all gastric ulcers and submucosal tumours, regardless of their appearances, were considered to be malignant at endoscopy so as to include all such lesions in the study.

\section{STATISTICAL ANALYSIS}

Statistical evaluation of the results of malignant lesions correctly identified by each technique was made using the $\chi^{2}$ test with or without Yates's correction as appropriate. Results were considered to be significant at $\mathrm{p}<0.05$.

\section{Results}

Of the 318 lesions sampled, malignancy was verified in 265 (oesophageal 99; gastro-oesophageal 38; gastric 72; colorectal 56) and benign lesions in 53 (Table I). There were 14 patients with submucosal malignancies: oesophagus 2 (squamous cell carcinoma of the lung presenting as dysphagia and producing a submucosal bulge of the oesophagus of over $4 \mathrm{~cm}$ ); stomach 6 (locally invasive pancreatic carcinoma producing intragastric nodular bulges 2 , lymphocytic lymphoma 2, leiomyosarcoma 1, and metastases from adenocarcinoma of the lung 1); and colon and rectum 6 (metastatic deposits in the pouch of Douglas 5 and lymphocytic lymphoma of the caecum 1). Eighty patients had squamous cell carcinoma, 181 adenocarcinoma. The study included two patients with early gastric cancers. There was no disparity in the cytological and histological diagnoses. The overall diagnostic accuracy achieved for all tumour types was $94 \%$ with needle aspiration cytology, which was significantly better $\left(\chi^{2}=11 \cdot 73, \mathrm{p}<0.005\right)$ than that of biopsy $(87 \cdot 2 \%)$ and brush cytology $(84 \cdot 9 \%)$. The diagnostic yield of the three techniques in relation to the site was not, however, significantly different (Table II).

Table III shows that the results of aspiration cytology compared with brush cytology and forceps biopsy gave significantly better results in submucosal malignancies $(92.9 \% v 7 \cdot 1 \%$ and $14 \cdot 3 \%$ respectively, $\left.\chi^{2}=26 \cdot 86, p<0.001\right)$; infiltrative malignancies $(95 \cdot 8 \% v 90 \cdot 1 \%$ and $78.9 \%$ 
TABLE IV Cumulative accuracy of the combination of various techniques

\begin{tabular}{llcl}
\hline & \multicolumn{3}{l}{ No(\%) of positive cases } \\
\cline { 2 - 4 } Techniques & $\begin{array}{l}\text { Primary } \\
\text { malignancies } \\
(n=251)\end{array}$ & $\begin{array}{l}\text { Submucosal } \\
\text { malignancies } \\
(n=14)\end{array}$ & $\begin{array}{l}\text { Total } \\
\text { malignancies } \\
(n=265)\end{array}$ \\
\hline $\begin{array}{l}\text { Biopsy+brush } \\
\text { cytology }\end{array}$ & $239(95)$ & $2(14)$ & $241(91)$ \\
$\begin{array}{l}\text { Biopsy+aspiration } \\
\text { cytology }\end{array}$ & $248(99)$ & $13(93)$ & $261(98)$ \\
$\begin{array}{c}\text { Biopsy+aspiration } \\
\text { cytology+brush } \\
\text { cytology }\end{array}$ & $249(99)$ & $13(93)$ & $262(99)$ \\
\hline
\end{tabular}

respectively, $\left.\chi^{2}=10 \cdot 16, \mathrm{p}<0 \cdot 01\right)$, and ulceronecrotic tumours $(90.9 \% v 36.4 \%$ and $45.6 \%$ respectively, $\left.\chi^{2}=7 \cdot 69, \mathrm{p}<0 \cdot 05\right)$. Although the reliability of all three techniques was not significantly different in ulcerative tumours, the forceps biopsy gave significantly better results in polypoid tumours (100\%) compared with brush cytology $(93.3 \%)$ and aspiration cytology (95\%) $\left(\chi^{2}=7.72, p<0.05\right)$

Table IV shows that the cumulative accuracy of biopsy and aspiration cytology was significantly better than that of a combination of biopsy and brush cytology $\left(\chi^{2}=15.08, \mathrm{p}<0.001\right)$. When cumulative results were analysed separately for mucosal and submucosal tumours a positive trend was observed for a combination of biopsy and aspiration cytology for both mucosal $\left(\chi^{2}=5.57, p<0.02\right)$ and submucosal tumours $\left(\chi^{2}=17.37, p<0.001\right)$. The addition of brush cytology to a combination of biopsy and aspiration cytology did not improve the diagnostic yield significantly.

Eleven samples (biopsy 2; needle aspirate 4; brush cytology 5) were reported as 'suspicious'; subsequently 10 of these were confirmed as malignant and the other one as benign. All specimens which were initially diagnosed as positive for malignancy were found to be positive, whereas one brush cytology specimen initially reported as not malignant was changed to a positive group and interpreted as initially underread specimen. Aspiration cytology gave a positive yield in 21 of the 24 lesions considered negative by both biopsy and brush cytology: submucosal 11; ulceronecrotic 5 ; infiltrative 4 ; ulcerative 1 . None of these lesions was suspicious by either biopsy or brush cytology. Aspiration cytology showed false negative results in 16 lesions (polypoid 6; infiltrative 3 ; ulcerative 5 ; ulceronecrotic 1 ; submucosal 1 ) and three of these were negative with brush cytology and biopsy as well. In nine the needle aspirate consisted of blood or tissue fluid and in the remaining seven of normal epithelial cells. In three malignant lesions with false negative histology and cytology malignancy was confirmed from surgically resected specimens. None of these sampling techniques contributed to any complication.

\section{BENIGN LESIONS}

There were 53 patients with benign diseases: mucosal 48, submucosal 5 . In each case of mucosal disease all techniques were interpreted correctly, that is, there were no false positives. Of the five patients with submucosal lesions, one had oesophageal tuberculosis, two had gastric leiomyoma, and one each had tuberculosis and actinomycosis of the right sided colon. Although aspiration cytology picked up the first three submucosal lesions, forceps biopsy was positive in oesophageal tuberculosis and brush cytology was negative in all. Needle aspirate from leiomyomas showed spindle shaped smooth muscle cells and was interpreted as a soft tissue tumour, probably a leiomyoma. In both colonic lesions all three techniques were negative, but needle aspirate yielded inflammatory cells. The resected specimen did not even show characteristic pathology of the tuberculosis. The final diagnosis of tuberculosis was made on the basis of clinical, radiological, and operative findings with response to antituberculous treatment.

\section{Discussion}

This study shows the overall diagnostic superiority of endoscopic fine needle aspiration cytology (94\%) to the conventional techniques of forceps biopsy $(87 \cdot 2 \%)$ and brush cytology $(84 \cdot 9 \%)$. The cumulative accuracy of biopsy and brush cytology was higher than either of the techniques alone; however, significantly better results were obtained when biopsy was combined with aspiration cytology. Needle aspiration was diagnostic in malignancies with a low yield with forceps biopsy and brush cytology, such as submucosal, infiltrative, and ulceronecrotic malignancies. Furthermore, this technique yielded positive results in 21 of 24 malignant lesions with false negative biopsy and brush cytology. Obviously, adding endoscopic fine needle aspiration to the existing sampling techniques is clearly an advance. The absence of any complications adds further value to this technique.

It is important when comparing the diagnostic accuracy of sampling techniques to be precise and comprehensive with regard to the gross characteristics of the lesions, as the yield of the sampling technique depends on it. ${ }^{13}$ It is also essential for accurate data analysis to include only the results of the first examination, as repeat sampling of the lesion with previously negative results may subsequently be productive, which would tend to bias the true accuracy.

Brush cytology is technically an easier procedure and has been widely used for the diagnosis of endoscopically visualised lesions. It improves diagnostic yield when combined with the biopsy technique. ${ }^{1-6}$ The diagnostic yield of brush cytology in the present series was $84.9 \%$, which improved to $89.2 \%$ if submucosal tumours were excluded from the analysis, and these data are in agreement with the results of others. ${ }^{1-6}$ The accuracy of biopsy diagnosis of $87 \cdot 2 \%$ compares well with that in other series. ${ }^{1-6}$ Our biopsy results would increase to $91 \cdot 2 \%$ if submucosal malignancies were excluded from the analysis. Although biopsy results were most impressive in polypoid lesions with an accuracy of $100 \%$, the yield was inferior to brush cytology in infiltrative lesions. The combination of biopsy and brush cytology improved the accuracy for mucosal tumours to $95 \cdot 2 \%$, which agrees with the results of others. ${ }^{37}$ The false negative results with 
both techniques were significantly higher for submucosal, ulceronecrotic, and infiltrative tumours, which has also been found by others. ${ }^{137-9}$

The diagnostic superiority of endoscopic fine needle aspiration cytology was related mainly to the macroscopic appearance of the malignancies. The diagnostic accuracy of aspiration cytology was significantly higher than that of biopsy or brush cytology in submucosal, infiltrative, and ulceronecrotic malignancies. The higher yield of needle aspiration in these lesions was due to its ability to allow adequate cytological sampling from the deeper layers. Although the numbers with submucosal and ulceronecrotic malignancies were small in our series, consistently gratifying results were obtained with aspiration cytology for such lesions. Biopsy and brush cytology are known to have a low yield for such malignancies. ${ }^{37-9}$ We found transproctoscopic fine needle aspiration cytology a simple and reliable technique for the definitive diagnosis of metastatic deposits in the pouch of Douglas. Furthermore, during the study three benign submucosal lesions - oesophageal, tuberculosis, and leiomyoma of the stomach - were correctly identified by endoscopic fine needle aspiration, which further attests to the diagnostic superiority of this technique for submucosal lesions. Several techniques, including lift and cut, well biopsy, and giant biopsy forceps techniques, have been used in an attempt to increase the diagnostic yield of submucosal lesions but with limited success and attendant complications. ${ }^{13}{ }^{14}$ The results of aspiration cytology were not significantly influenced by the site of the malignancy. The false negative rates were significantly lower when aspiration cytology was combined with biopsy $(1 \cdot 5 \%)$ compared with a combination of brush cytology and biopsy (9.1\%).

The negative yield with aspiration cytology was largely due to needle puncture into the nonrepresentative area. The number of false negative results would possibly decrease by making three to four passes at different sites into the target lesion without removing needle aspiration equipment from the scope channel between aspirations as required for forceps or brush procedures since the fine needle catheter acts as a reservoir during sampling.

We conclude that endoscopic fine needle aspiration cytology is a simple, rapid, safe, and highly accurate method for the diagnosis of endoscopically visualised malignancies and is of particular value in submucosal, ulceronecrotic, and infiltrative malignancies. It should be routinely combined with conventional techniques in an attempt to increase the yield for the diagnosis of gut malignancies.

1 Witzel L, Holter F, Gretillat PA, Scheurer U, Keller M Evaluation of specific value of endoscopic biopsies and brush cytology for malignancies of the oesophagus and stomach. Gut 1976; 17: 375-7.

2 Winawer SJ, Leidner SD, Hagdu SI, Sherlock P Colonoscopic biopsy and cytology in the diagnosis of colon. Colonoscopic biopsy and cyt

3 Qizilbash A, Castelli M, Kowalski M, Churly A. Endoscopic brush cytology and biopsy in the diagnosis of cancer of the upper gastrointestinal tract. Acta Cytol 1980; 24: 313-8.

4 Chambers LA, Clark WE. The endoscopic diagnosis of gastroesophageal malignancy. Acta Cytol 1986; 30: 70-114

5 Chen YL. The diagnosis of colorectal cancer with cytologic brushings under direct vision at fiberoptic colonoscopy. A report of 59 cases. Dis Colon Rectum 1987; 30: 342-4

6 Jan GM, Dewani K, Koul V, Zargar SA. Role of brush cytology in GIT and biliary tract lesions. Ind $\mathcal{F}$ Cancer 1988; 25: 22-8.

7 Winawer SI, Posner G, Lightdale CJ, Sherlock P, Melamed M Fortner JG. Endoscopic diagnosis of advanced gastric cancer: factor influencing yield. Gastroenterology 1975; 69: 1183-7.

8 Kobayashi S, Prolla JC, Winans CS, Kirsner JB. Improved endoscopic diagnosis of gastroesophageal malignancy: combined use of direct vision brushing cytology and biopsy. bined use of direct vision

9 Young JA, Hughes HE. Three year trial of endoscopic cytology of the stomach and duodenum. Gut 1980; 21: cytology

10 Kochhar R, Rajwanshi A, Malik AK, Gupta SK, Mehta SK. Endoscopic fine needle biopsy of gastroesophageal malig nancies. Gastrointest Endosc 1988; 34: 321-3.

11 Ingoldby CJH, Mason MK, Hall RI. Endoscopic needle aspiration cytology: a new method for the diagnosis of upper gastrointestinal cancer. Gut 1987; 28: 1142-4.

12 Richards WCD, Spriggs AI. The cytology of gastric mucosa. f Clin Pathol 1961; 14: 132-9.

13 Winawer SJ. Tissue diagnosis in upper gastrointestinal malignancy. Gastroenterology 1982; 82: 379-82.

14 Kaneko E, Kumagai J, Honda N, Nakamura S, Kino I. Evaluation of the new giant-biopsy forceps in the diagnosis of mucosal and submucosal gastric lesions. Endoscopy 1983; 15: $322-6$. 